\title{
THE STRUCTURAL BEHAVIOR OF HYBRID STRUCTURAL INSULATED PANELS UNDER PURE BENDING LOAD
}

\author{
Jauhar Fajrin $^{1 *}$, Yan Zhuge ${ }^{2}$, Frank Bullen ${ }^{3}$, Hao Wang ${ }^{3}$ \\ ${ }^{1}$ Department of Civil Engineering, Faculty of Engineering, University of Mataram, \\ Mataram 83125, Indonesia \\ ${ }^{2}$ School of Natural and Built Environments, University of South Australia, \\ Adelaide, South Australia 5000, Australia \\ ${ }^{3}$ School of Civil Engineering and Surveying, University of Southern Queensland, \\ Toowoomba, QLD 4350, Australia
}

(Received: September 2015 / Revised: March 2017 / Accepted: September 2017)

\begin{abstract}
This paper presents the structural behavior of newly-developed hybrid structural insulated panels (SIPs) formed by incorporating lignocellulosic composites-jute fiber composite (JFC) and medium-density fiber (MDF) - as intermediate layers between aluminum skin and an expanded polystyrene (EPS) core. The investigation was conducted as an experimental work. A four-point bending load was performed to create pure bending conditions, and the samples were prepared in accordance with ASTM C 393-00 standards. Testing was performed using a $100 \mathrm{kN}$ servo-hydraulic machine with a loading rate of $5 \mathrm{~mm} / \mathrm{min}$. The results show that the incorporation of intermediate JFC or MDF layers enhanced the flexural behavior of the SIPs. The ultimate loads of hybrid SIPs with JFCs or MDF were, respectively, approximately $62.59 \%$ and $168.58 \%$ higher than the ultimate load achieved by SIPs without intermediate layers. Hybrid SIPs exhibited a much larger area under the load-deflection curve than those of conventional SIPs; this points to the toughness of the material and its ability to sustain larger compression strain prior to reaching their ultimate loads, which prevents them from prematurely failing under buckling or indentation.
\end{abstract}

Keywords: Hybrid structure; Insulated panels; Pure bending; Structural behavior

\section{INTRODUCTION}

Composite sandwich panels that can be manufactured rapidly, cheaply, and in copious amounts can meet all requirements of an optimal building component. Previously, composite sandwich panels have been widely used in manufacturing industries, but continued development has allowed them to become a viable choice in other applications, such as civil and building infrastructure. A high strength-to-weight ratio is the most recognized advantage of composite sandwich panels (Davies, 2001), and they also have excellent insulation properties (Zenkert, 1995). An additional advantage of composite sandwich panels, due to their lightweight properties, is that they have good resistance to earthquakes. Mistler and Valls (2004) stated that sandwich construction systems may reduce the mass of buildings by $70 \%$ compared to traditional European floor systems.

An earthquake's force is related to its acceleration and the mass of the buildings it hits; the

*Corresponding author's email: jauhar.fajrin@unram.ac.id, Tel: +62-0370-638436, Fax: +62-0370-636523 Permalink/DOI: https://doi.org/10.14716/ijtech.v8i5.861 
heavier the building, the more force is exerted. Reducing the mass of structures and buildings is thus the most critical factor in decreasing the risk of earthquake damage (Ergul et al., 2003). Some researchers relate earthquake-resistant housing to sustainability. Lewis (2003) stated that damage and destruction caused by natural hazards is the arch-indicator of non-sustainable development, so earthquake-resistant buildings are seen as a prerequisite in sustainable housing. Many countries have their own criteria for sustainability, including those in Southeast Asia; Bakar et al. (2011) reported their work on developing a sustainability index for housing in Malaysia. While in Indonesia, Firmawan et al. (2016) introduced a green construction site index (GCSI) to evaluate whether ongoing projects were conducive to sustainable green construction.

SIPs are believed to be the most successful application of composite sandwich panels in the housing industry. The panels are made by sandwiching a rigid insulation foam core between two skins, which are typically made of oriented strand board (OSB) (Morley, 2000). Besides providing excellent structural integrity, SIPs ensure greater environmental sustainability (Tracy, 2000) and can provide strong, energy-efficient insulation for buildings (Andrews, 1992; Mullens \& Arif, 2006). The greatest advantage of SIPs is that they allow structural support and insulation to be incorporated into a single system, which enables greater durability (Kermany, 2006). OSB is commonly used for the skin of SIPs, but the possibility of mold build-up and disintegration in water limits OSB's use as a skin (Vaidya et al., 2010). Kawasaki et al. (1999) developed a wood-based sandwich panel with a low-density fiberboard core with different face materials for structural insulated walls and floors, and the results showed that low-density fiberboard's heat retention properties were superior to current commercial insulators, such as plastic foams and mineral wools. In addition, Vaidya et al. (2010) developed an innovative composite structural insulated panel (CSIP) using E-glass fibers blended with a polypropylene matrix for the skins and an EPS foam core, which was designed for the exterior walls of a modularized structure. Furthermore, Kalyankar and Uddin (2011) researched developing SIPs with natural fiber laminate skin. The sandwich panel consists of JFC skins and an EPS core. Under the bending test, NSIPs sustained $190 \%$ more bending stress than traditional OSB SIPs and $70 \%$ weight reduction compared to OSB SIPs. More recently, Uddin and Du (2014) reported their work on new thin shells made of composite structural insulated panels and confirmed that the new SIPs were not only usable, but also competitive.

The work reported in this paper highlights the comprehensive development of hybrid structural insulated panels that incorporate lignocellulosic composites as intermediate layers. The preliminary experiments were conducted using simple comparative experiments (Fajrin et al., 2011) and single-factor experimental design (Fajrin et al., 2011). The preliminary works were focused on selecting appropriate materials for both core and intermediate layers. It was found that EPS foam was a suitable choice for the core, while MDF performed well for the intermediate layer materials. Further development of the project that used natural fiber composites for the intermediate layer recommended JFC as a suitable intermediate layer material (Fajrin et al., 2013). More recently, a comprehensive analysis of the flexural behavior of the newly-developed panel in the medium-scale experiment was also reported (Fajrin et al., 2016). The final stage of this project was developing a structural component in a full-scale experiment that could be used in building structures, which was made up of hybrid SIPs. The hybrid SIPs in this research were made by inserting JFC and MDF as intermediate layers in between aluminum skins and an EPS core. The basic concept of hybrid SIPs investigated in this research follows the work of Mamalis et al. (2008), who introduced the concept of hybrid sandwich panels with intermediate layers.

This paper discusses the flexural behavior of the newly-made SIPs under pure bending load in a full-scale experiment, which includes comparing ultimate load with failure modes, loaddeflection, and load-strain behavior. For comparison purposes, the performance of hybrid SIPs 
was compared to that of conventional SIPs.

\section{EXPERIMENTAL PROCEDURES}

All experimental work, including sample preparation and structural testing, was conducted at the Centre of Excellence in Engineered Fiber Composites (CEEFC), University of Southern Queensland (USQ), Australia. The skins of the hybrid sandwich panels were prepared using aluminum sheet $5005 \mathrm{H} 34$, while Isolite ${ }^{\circledR}$ EPS was used for the core. Two types of materials were used for the intermediate layers: JFC and MDF. The characteristics of the skin and core materials are shown in Table 1.

Table 1 Characteristics of the skin and core materials

\begin{tabular}{llll}
\hline \multicolumn{2}{c}{ Core: Isolite $^{\circledR}$ EPS } & \multicolumn{2}{c}{ Skin: Aluminum $5005 \mathrm{H} 34$} \\
\hline Grade & $: \mathrm{VH}(\mathrm{Very}$ High $)$ & Density $(\rho)$ & $: 2700 \mathrm{~kg} / \mathrm{m}^{3}$ \\
Density $(\rho)$ & $: 28 \mathrm{~kg} / \mathrm{m}^{3}$ & Modulus Elasticity $(\mathrm{E})$ & $: 68.2 \mathrm{GPa}$ \\
Modulus Elasticity $(\mathrm{E})$ & $: 7250 \mathrm{kPa}(7.25 \mathrm{MPa})$ & Poisson ratio & $: 0.33$ \\
Poisson ratio & $: 0.35$ & Shear modulus & $: 25.9 \mathrm{GPa}$ \\
Flexural strength & $: 337 \mathrm{kPa}$ & Shear strength & $: 96.5 \mathrm{MPa}$ \\
Shear stress & $: 240 \mathrm{kPa}$ & Ultimate tensile strength & $: 159 \mathrm{MPa}$ \\
& & Yield tensile strength & $: 138 \mathrm{MPa}$ \\
\hline
\end{tabular}

The samples were sized to be $1150 \times 100 \times 52 \mathrm{~mm}$ with a span length of $900 \mathrm{~mm}$. The aluminum skin's thickness was $1 \mathrm{~mm}$, while the thickness of the intermediate layers was $5 \mathrm{~mm}$. A $50 \mathrm{~mm}$ thick EPS was used for the control (the SIP without an intermediate layer) and a $40 \mathrm{~mm}$-thick one was used in both hybrid panels (the SIPs with intermediate layers), making the panels' thickness no more than $52 \mathrm{~mm}$. The experiments for each variable panel were conducted four times for a total of 12 beams being sampled. The properties of each intermediate layer are presented in Table 2, while a cross-section view of the samples is shown in Figure 1.

Table 2 Properties of intermediate layer materials

\begin{tabular}{lcc}
\hline \multicolumn{1}{c}{ Mechanical properties } & Medium-Density Fiber (MDF) & Jute Fiber Composite (JFC) \\
\hline Modulus Elasticity (E) & $: 4000 \mathrm{MPa}$ & $: 4502 \mathrm{MPa}$ \\
Poisson ratio & $: 0.25$ & $: 0.361$ \\
Tensile strength & $: 18 \mathrm{MPa}$ & $: 42.44 \mathrm{MPa}$ \\
Shear strength & $: 2500 \mathrm{MPa}$ (modulus) & $: 27.7 \mathrm{MPa}$ \\
Flexural strength & $: 18 \mathrm{MPa}$ & $: 56.23 \mathrm{MPa}$ \\
Compressive strength & $: 10 \mathrm{MPa}$ & $: 57.26 \mathrm{MPa}$ \\
\hline
\end{tabular}

A four-point bending test was performed to create pure bending conditions. This testing arrangement is preferred because it has the advantage of uniform tensile or compressive stresses with zero shear being produced over the area between the loading points (Harte et al., 2000). The test was performed in accordance with ASTM C 393-00 standards (ASTM, 2000), which outline the required properties of flat sandwich constructions subjected to flatwise load. A 100 $\mathrm{kN}$ servo-hydraulic machine with a loading rate of $5 \mathrm{~mm} / \mathrm{min}$ was used for the testing process. A System 5000 data logger was then used to obtain applied load, displacement, and strain data. The test setup can be seen in Figure 2. 


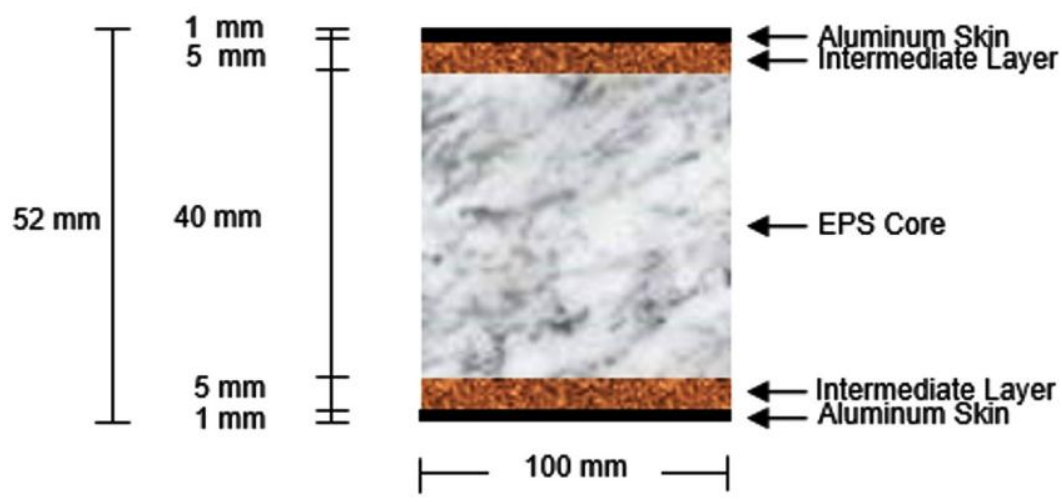

(A)

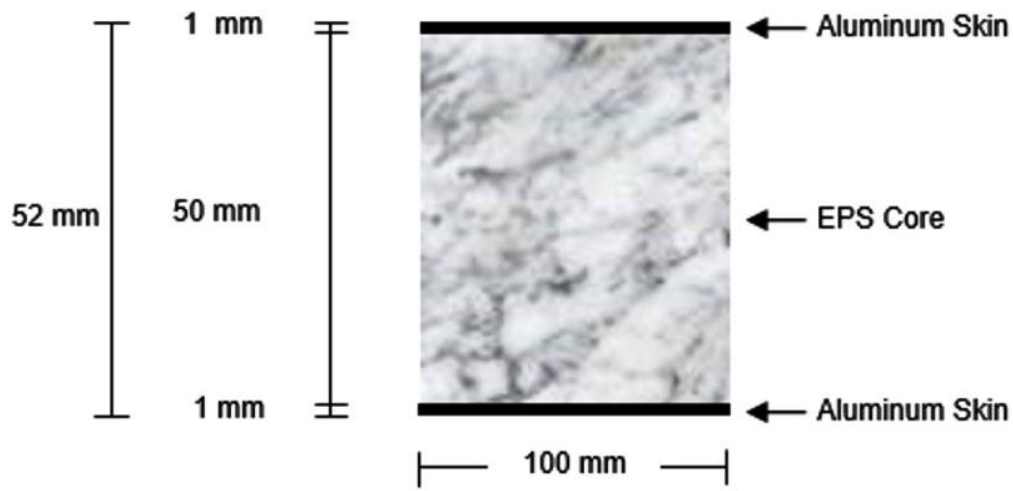

(B)

Figure 1 A cross-section view of the sample: (A) hybrid sandwich panel; (B) conventional sandwich panel
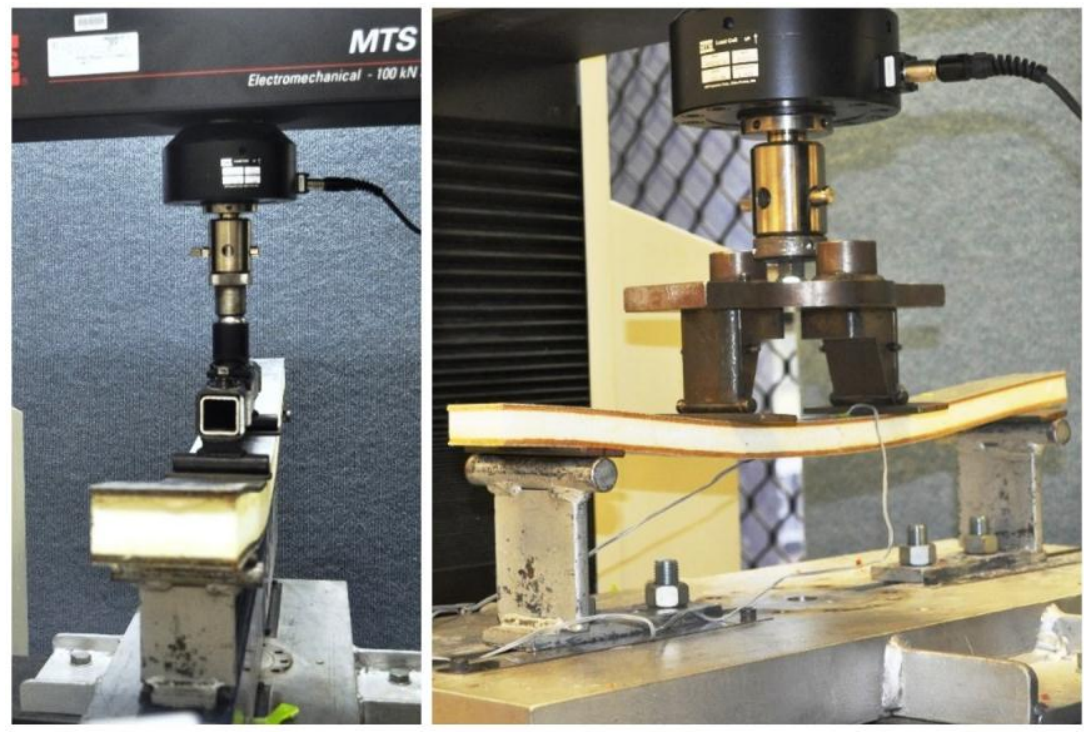

Figure 2 The setup of the four-point bending test

\section{RESULTS AND DISCUSSION}

\subsection{Comparison of Ultimate Loads and Failure Modes}

The results of flexural testing on SIPs are provided in Table 3. The average ultimate load capacity of conventional SIPs (CTR) was $496.5 \mathrm{~N}$, while that of SIPs with JFC and MDF intermediate layers was $807.25 \mathrm{~N}$ and $1333.5 \mathrm{~N}$, respectively. It is also clearly shown in Figure 3 that the load carrying capacity of hybrid SIPs with JFC is $62.59 \%$ higher than those of 
conventional SIPs. More significant improvement is achieved when MDF is employed for the intermediate layer, making the carrying capacity approximately $168.58 \%$ higher instead of $62.59 \%$. Furthermore, hybrid SIPs with MDF intermediate layers sustained $65.19 \%$ higher load than the hybrid SIPs with JFC intermediate layers. However, there is some concern about the maximum achieved loads among the samples; for instance, sample 4 in the CTR group has an ultimate load of $407 \mathrm{~N}$ with a deflection of $10.18 \mathrm{~mm}$. In contrast, sample 2 sustained more load $(572 \mathrm{~N})$ and only deflected about half of the sample $4(5.7 \mathrm{~mm})$. Similarly, the deflection of sample 4 within the JFC group, which is $61.11 \mathrm{~mm}$, is almost double the rest of the samples. This phenomenon is normal in sandwich panel testing and analysis where the final achieved loads are determined by the mode of failure encountered. The failure mechanism of the sandwich structure that occur under bending load may arise from various mechanisms (Zenkert, 1995), including compression or tension failure of the skins, core shear, wrinkling, local indentation, debonding at the interface of core and facing, and global buckling (Daniel, 2009). More specifically, sandwich panels with foam core are likely to fail due to indentation, face wrinkling, or core shear (Mamalis et al., 2008), which may result in lower load carrying capacities. Further analysis about this phenomenon is given in the next part about failure mode mechanism. Although there are significant differences between the ultimate loads, the maximum loads and deflections within the elastic region-which are extremely important to consider when using sandwich panels as a building material-are reasonably similar. The coefficient of variations (CV) values are also within the range of acceptable values.

Table 3 The results of flexural testing

\begin{tabular}{ccccccr}
\hline \multirow{2}{*}{ No } & \multicolumn{2}{c}{ CTR } & \multicolumn{2}{c}{ JFC } & \multicolumn{2}{c}{ MDF } \\
\cline { 2 - 7 } & $\begin{array}{c}\text { Load } \\
(\mathrm{N})\end{array}$ & $\begin{array}{c}\text { Deflection } \\
(\mathrm{mm})\end{array}$ & $\begin{array}{c}\text { Load } \\
(\mathrm{N})\end{array}$ & $\begin{array}{c}\text { Deflection } \\
(\mathrm{mm})\end{array}$ & $\begin{array}{c}\text { Load } \\
(\mathrm{N})\end{array}$ & $\begin{array}{c}\text { Deflection } \\
(\mathrm{mm})\end{array}$ \\
\hline 1 & 489.00 & 8.58 & 898.00 & 39.36 & 1241.00 & 16.53 \\
2 & 572.00 & 5.70 & 751.00 & 38.72 & 1537.00 & 26.4 \\
3 & 518.00 & 7.84 & 842.00 & 36.69 & 1275.00 & 19.41 \\
4 & 407.00 & 10.18 & 738.00 & 61.11 & 1281.00 & 24.58 \\
\hline Average & 496.50 & 8.08 & 807.25 & 43.97 & 1333.50 & 21.73 \\
\hline StDev & 68.87 & 1.86 & 76.16 & 11.48 & 136.81 & 4.56 \\
\hline CV & 13.87 & 23.01 & 9.43 & 26.10 & 10.25 & 20.98 \\
\hline
\end{tabular}

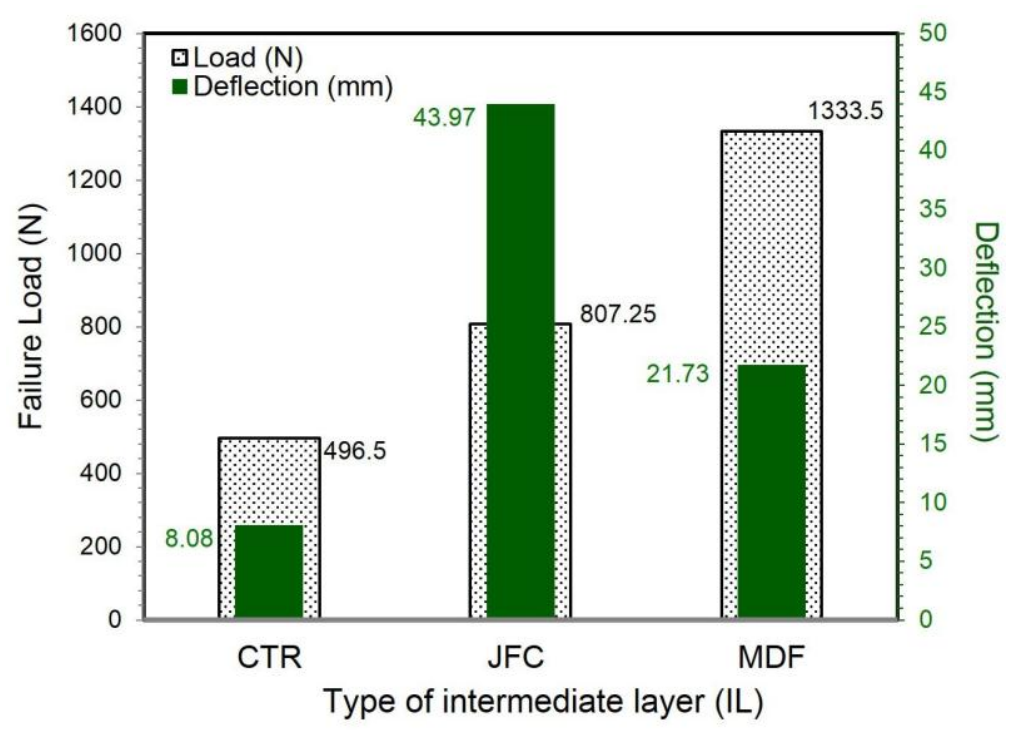

Figure 3 The average maximum load carrying capacity and deflection against intermediate layers 
Figure 4 shows several dominant failure modes observed during the bending test. The failure mechanisms for CTR panels include diagonal shear crack, vertical shear crack, and debonding at the interface of core and skin. The shear failure was initiated by a single crack at the bottom underneath the loading point. The crack then spread towards the inner roller point at the top, forming a vertical crack pattern with an angle of almost 900. As loading continued, the bottom crack grew, triggering a delamination between core and skin. According to Mirzapour et al. (2005), this failure mechanism was governed by the foam core and is called a foam core stretching phenomenon. The foam core cell stretched at the tension side of the specimen as the load increased, initiating multiple cracks at the lower part just below the inner roller.

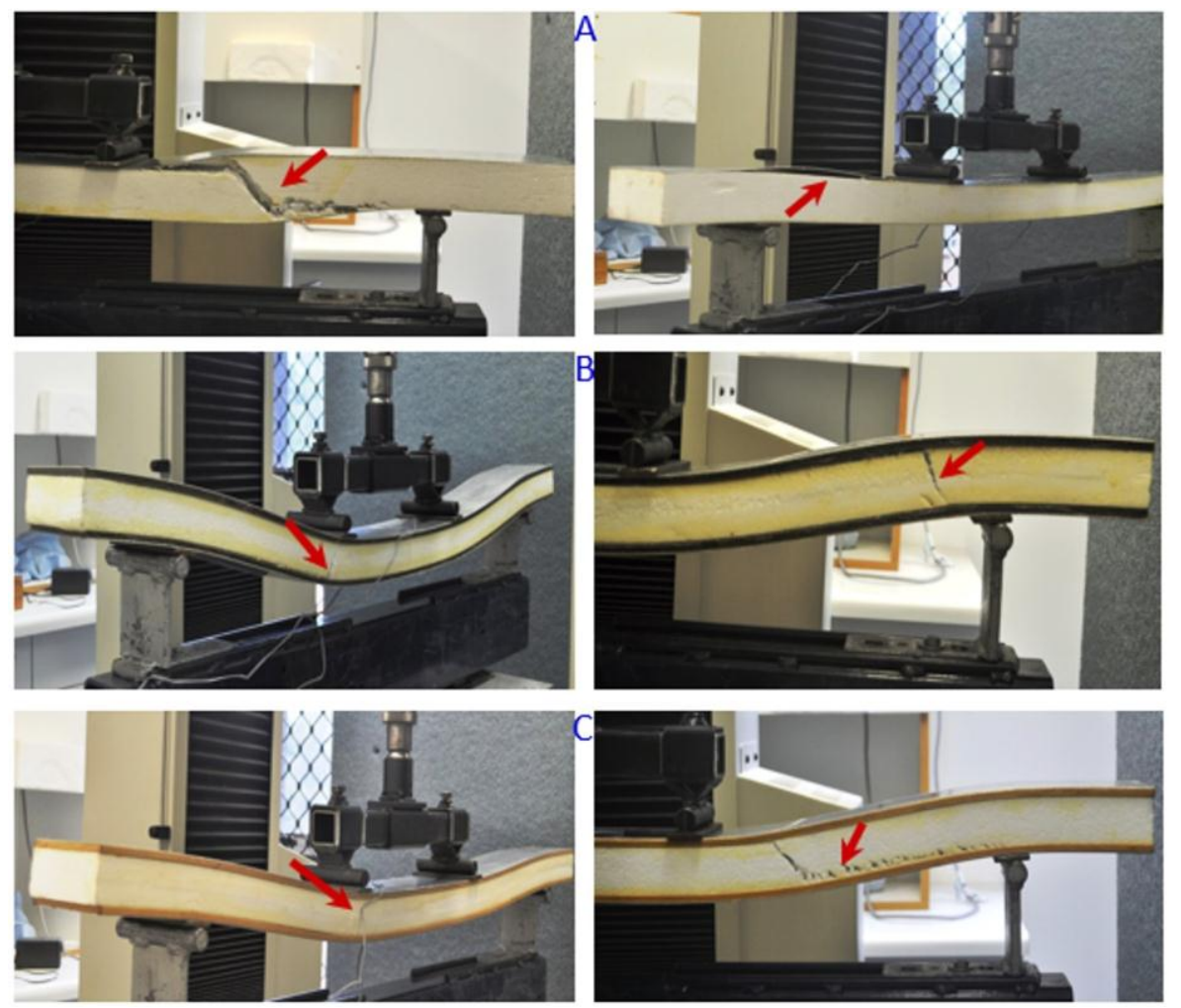

Figure 4 Failure mechanisms of the conventional and hybrid structural insulated panels

Another type of failure mechanism observed was the debonding at the interface of the core and skin at the upper part. The debonding started near the loading point and quickly spread along the interface towards the edge of the specimen. Such failure was also common in sandwich panel beams tested under flexural load (Mahfuz et al., 2004; Mirzapour et al., 2005). It seems that the primary reason for this specific failure mechanism was the weak bond strength at the interface of the skin and the core. It is clearly shown in Figure 4A that there was no trace of EPS foam core on the debonded interface, meaning that the bond strength was significantly lower than the shear strength of the core. Figure 4B shows the failure modes of the hybrid sandwich panels with the JFC intermediate layers. This type of hybrid SIP collapsed under two categories of failure modes: delamination of the core-intermediate layer and shear failure of the core. The shear failure of the core was frequently accompanied by the debonding mechanism at the interface of the core and intermediate layer. Parallel to the shear failure of the core in other specimen groups, the failure mechanism began with an individual crack that initiated either near the loading point or the support roller, both within the shear span of the specimens. The cracks then spread as the loading increased and they terminated at a point near the support roller. 
The failure mechanism of hybrid SIPs with MDF intermediate layers is depicted in Figure 4C. As seen in the figure, the principle failure mode of this sample category was shear failure of the core, with or without debonding at the interface of the core and intermediate layers. In contrast to the debonding mechanism in the JFC hybrid SIPs caused by the weak bond strength throughout the length of the specimen, the mechanism in this sample category occurred only within the shear region. It is important to note that the observed shear core failure within hybrid SIPs likely occurred due to excessive shear deformation of the soft core under large deflection, which a previous finding suggests (Sharaf et al., 2010). The other failure mechanism was a longitudinal shear failure of the core initiated at the edge of the specimen. As shown in this figure, a significant amount of the EPS core was left with the intermediate layers at the debonded interface. This suggests that the bond strength at the interface of the core-intermediate layer exceeded the compression strength of the core resulting in higher load-bearing capacity of the specimens. Therefore, the significantly increased ultimate loads that hybrid SIPs carry can be related to the presence of intermediate JFC or MDF layers within the sandwich structure. The intermediate layers provided reasonable support for the thin aluminum skin to carry the bending loads and prevented premature failure mechanisms such as indentation or delamination of the skin and core, which was observed in the conventional SIPs without intermediate layers. It is also important to note that there was no observed failure at either the intermediate layers, the skin of the hybrid SIPs, or the interface between them. This indicates that the flexural loads had been transferred to the core of the sandwich panel, which resulted in core shear failure that triggered debonding at the interface of the core and intermediate layers. The results confirmed a previous finding that stated hybrid sandwich panels with intermediate layers are superior to equivalent aluminum structures and conventional sandwich panels (Mamalis et al., 2008). It also confirmed that sandwich panels with a soft core are more vulnerable to compression of the skin, which may result in lower strength (Sharaf et al., 2010).

\subsection{Comparison of Load-Deflection and Load-Strain Behavior}

The comparison of the load-deflection behavior of SIPs is presented in Figure 5. It is clear in the figure that the load carrying capacity of hybrid SIPs is much higher than conventional SIPs. In fact, all the tested SIPs were ductile, which is desirable in building components for structural applications.

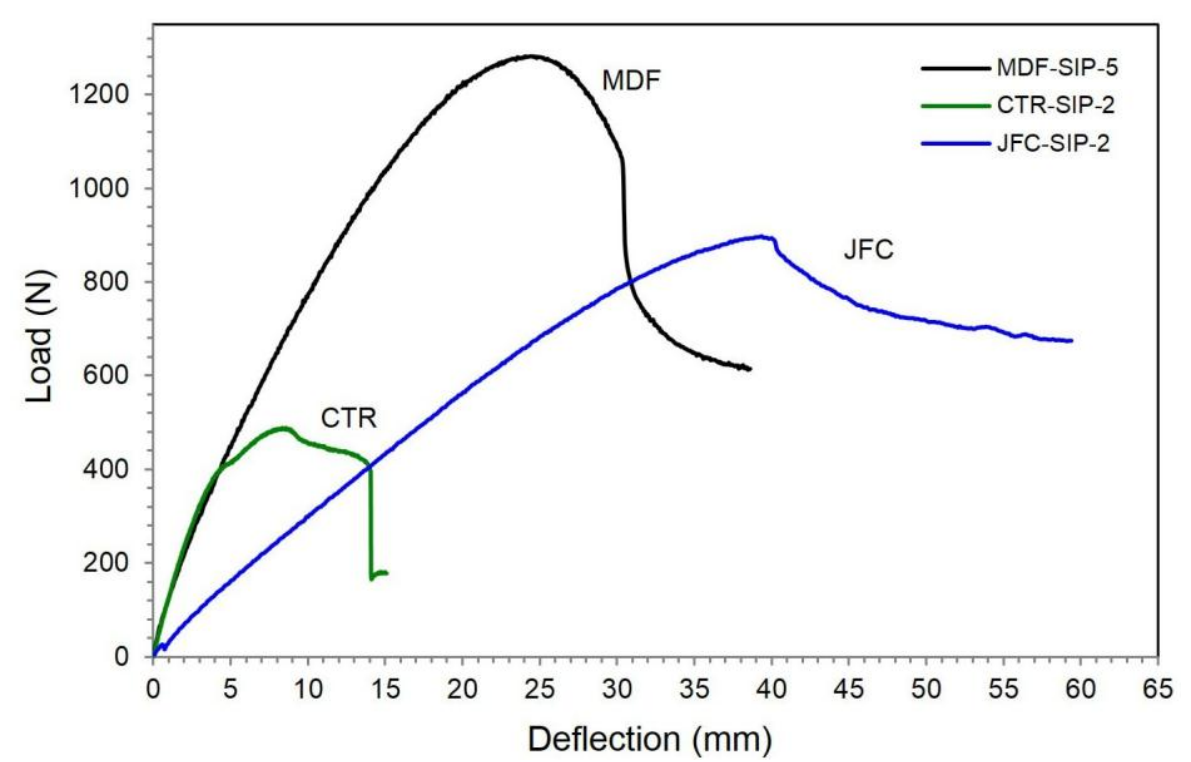

Figure 5 Comparison of load-deflection graphs of representative samples from the CTR, JFC, and MDF specimen groups 
In this graph, only one of the four samples was randomly chosen from each category for comparison purposes. A sample labelled MDF-SIP-5 was chosen from the MDF category, while CTR-SIP-2 and JFC-SIP-2 were randomly selected from the CTR and JFC categories, respectively. The load-deflection curves of all tested samples do not show a distinct yield point prior to failing and then forming a plastic region beyond the ultimate load. The initial sections of the curves in the graph were quite linear, which may be due to the linear elastic deformation of the cell structures. Mirzapour et al. (2005) explained that in sandwich panels with a foam core, the slope of the load-deflection curve will change as the cell ruptures due to stretching. After reaching the yield point, the foam will deform almost uncontrollably and finally collapse at the maximum applied load. In general, the lines departed in straight diagonals and then diverged upwards to reach their respective ultimate loads. The load decreased gradually beyond the peak load, while deflection steadily increased until the testing was automatically terminated.

As Figure 5 shows, hybrid SIPs with MDF intermediate layers are much stiffer than both hybrid SIPs with JFC intermediate layers and conventional SIPs (CTR). The CTR sample reached its ultimate load of approximately $490 \mathrm{~N}$ at a deflection of $10 \mathrm{~mm}$ while the JFC specimen reached the same load at the deflection of approximately $20 \mathrm{~mm}$. Hybrid SIPs with MDF intermediate layers reached a similar load at slightly less deflection, which was approximately $7.5 \mathrm{~mm}$. In general, although hybrid SIPs with JFC intermediate layers were less stiff than those with MDF intermediate layers, the ductile attribute of this type of panel has an additional advantage of being safer when utilized in buildings. Fiber-reinforced polymer (FRP) such as JFC laminate, which was used as intermediate layers within this sandwich structure, tends to flex instead of break, and this makes for good earthquake resistance (Hota \& Liang, 2011). Theoretically, SIPs with JFC intermediate layers should be stiffer than CTRs. It seems that the difference in collapse mechanisms - where the JFC panel failed due to delamination process while CTR panel collapsed due to core shear-resulted in the JFC panel being less stiff, since stiffness is a function of load and deflection. The deflection in the CTR panel immediately stopped when the panel abruptly collapsed under a combination of face compression and core shear when no more load could be carried by the structure. Meanwhile, the deflection in the JFC panel increased continuously even though the delamination process had initiated between the interface of the intermediate layers and the core. The JFC panel still carried significant load using its skin and intermediate layers and continuously deflected until the testing process was terminated. The early delamination process at the interface of the intermediate layers and the core may have resulted from the low bond strength of the two adjacent materials. Kim and You (2015) and Fajrin et al. (2016) reported a similar failure mechanism for sandwich structures with EPS and XPS foam core.

Furthermore, there is an obvious advantage to incorporating intermediate layers into SIPs that relates to the toughness of the material and the load carrying capacity. Toughness represents a material's ability to support loads, even after yielding or forming cracks (Somayaji, 1995). The toughness of a material can be measured as the area under the load-deflection curve. The hybrid SIPs exhibited a larger area under the load-deflection curve than those of conventional SIPs, thus indicating a hybrid SIPs' superior toughness. It is also worth noting that although hybrid SIPs with a JFC intermediate layer are less stiff than those with an MDF intermediate layer, the larger area under the load-deflection curve indicates they are tougher. Furthermore, Somayaji (1995) described that an increase in toughness relates to an increase in the amount of energy required to produce specific damage conditions. He also stated that materials' strength and stiffness may be the most important properties when considering the suitability of a material for use in building. Strength defines the collapse load while stiffness ensures that a structure does not deflect too much under load. These two properties are related to the elastic range of loaddeflection or stress-strain graph. However, it is also of comparable importance to consider that 
the plastic region develops beyond the proportional limit, which is related to the ductility of a material. Plastic region is the region in which the material deforms permanently. Material which has large portion of plastic region will undergo a large amount of plastic deformation prior to collapse. When a building faced with unexpected extreme loads such as earthquakes, the plastic region becomes crucial as a large amount of energy being absorbed by the materials is mainly contributed by the plasctic region. As it was observed, the hybrid SIPs withstand large deflections before rupture, which is extremely important when considering them for buildings in which a considerable warning would be required before total collapse. Hence, a building that made of the newly-developed SIPs which has a higher toughness is able to withstand such unexpected high loads for a long period of time so as to allow more time for occupants to escape.

Figure 6 shows the comparison of load-strain curve for the three different sample categories of tested structural insulated panels. The longitudinal strains were recorded by attaching strain gauges at the middle top surface (compression) and bottom surface (tension) of the tested panels. As initially predicted based on the constituent material properties, the load-strain curves show a non-linear evolution of strains. The skins and core material used within the sandwich structures were made of aluminum and EPS, which are ductile in nature and typically behave in a non-linear fashion. The load-strain evolution of sandwich structure can be expected based on the individual behavior of constituent materials (Tuwair et al., 2016). It is clearly shown by the load-strain graphs that the hybrid SIPs (JFC and MDF) possessed a higher capacity than CTRs.

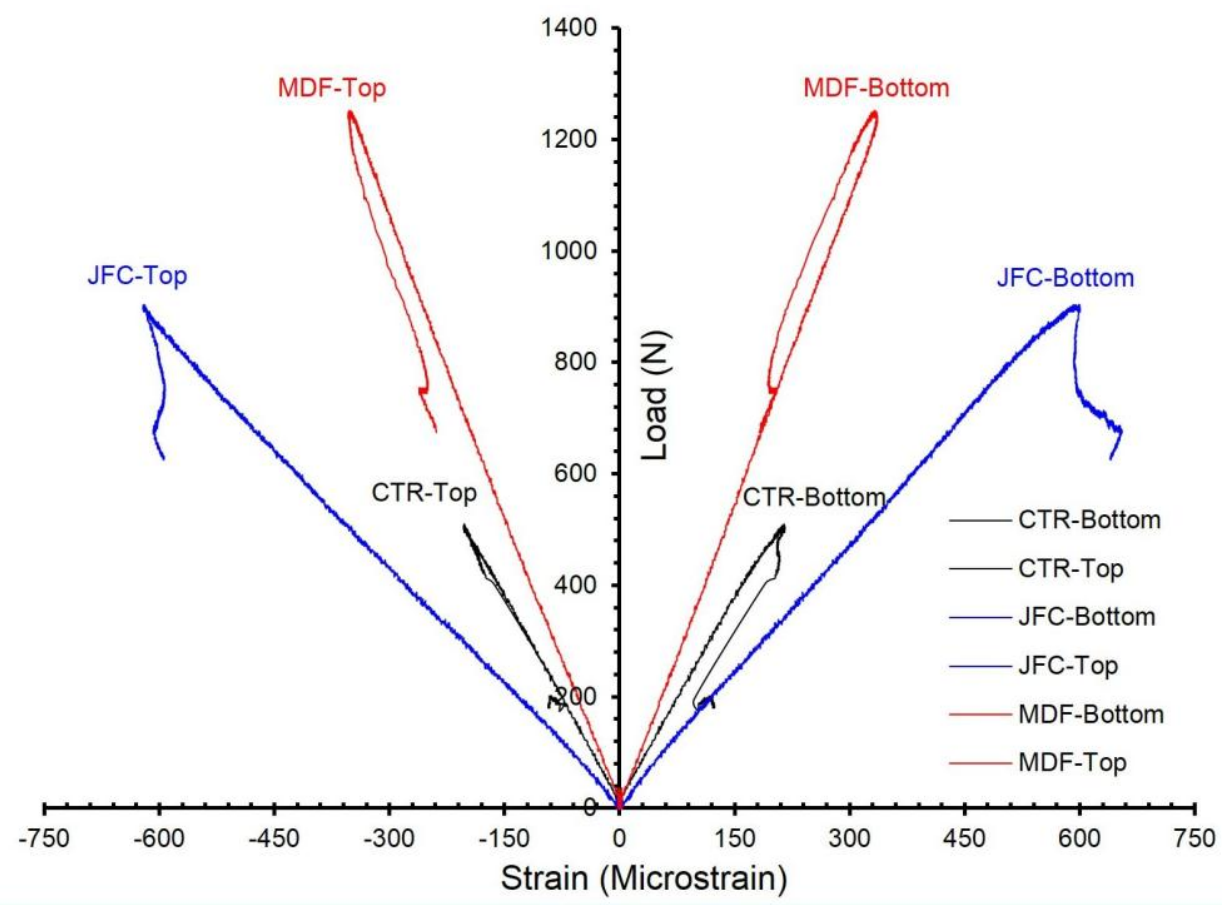

Figure 6 Comparison of load-strain relationship for structural insulated panels (SIPs)

The figure also highlights that the top and bottom surface strains for all specimen categories (CTR, JFC and MDF) have similar strain values within their own categories. For example, the representative curves for the CTR group have a similar strain values for both compression and tension sides at 210 microstrains. Slightly different strain values were found in the MDF specimen: 330 microstrains in tension and 360 microstrains in compression. Comparable strains were also observed for the JFC specimen; its strain for compression and tension sides was 620 microstrains and 600 microstrains, respectively. It is also worth noting that the CTR specimen 
failed at 210 microstrains, which was only $58 \%$ the strain of the MDF specimens and 35\% the compression strain of the JFC specimen. It seems that the aluminum skin on the CTR samples was not optimally utilized due to the sandwich panel's premature failure under the combination of face compression buckling and core shear. The curve for each sample category indicated that the strains at both sides of the sandwich panels increased linearly with the load early on and then started to deviate until they reached their ultimate loads. The strain evolution was reasonably similar to that shown in Daniel and Abot (2000), who noted that the strains in the skins deviated from linearity after the initiation of the first failure mechanism and progressed differently for the two skins up until failure. Overall, the introduction of intermediate layers helps hybrid SIPs to sustain larger compression strains prior to reaching their ultimate loads, which prevents them from prematurely failing under compression buckling. This finding also corroborated some earlier work in this field (Mamalis et al., 2008).

\section{CONCLUSION}

The experimental investigation of hybrid structural insulated panels (SIPs) with intermediate layers has been carried out under a four-point static bending load to create pure bending conditions. The bending behavior of hybrid SIPs has been compared to conventional SIPs without intermediate layers. The results show that the incorporation of intermediate layers made of lignocellulosic composites enhanced the structural behavior of SIPs under pure bending load. More specific outcomes are outlined as follows: (1) The load carrying capacity of hybrid SIPs with JFC and MDF was approximately $62.59 \%$ and $168.58 \%$ higher than the conventional SIPs without intermediate layers, respectively; (2) All tested specimens of structural insulated panels behave in a ductile manner. However, hybrid structural insulated panels developed much large area under the load-deflection curve than those of conventional sandwich panels which related to the toughness of the material; (3) The incorporation of intermediate layers within hybrid SIPs helps them sustain larger compression strain before reaching their ultimate loads that has prevented them to prematurely fail under buckling or indentation resulting in higher flexural ultimate load carrying capacity.

\section{REFERENCES}

Andrews, S., 1992. Foam Core Panels and Buildings Systems. Second Edition, Cutter Information Corp., Arlington, Massachusetts, USA.

ASTM Standard C 393-00, 2000. Standard Test Method for Flexural Properties of Sandwich Construction. ASTM International. Philadelphia, PA (19103)

Bakar, A.H.A., Cheen, K.S., Rahmawaty, 2011. Sustainable Housing Projects in Malaysian Housing Development: Towards Establishing Sustainability Index. International Journal of Technology, Volume 2(1), pp. 84-93

Daniel, I.M., 2009. Influence of Core Properties on the Failure of Composite Beams. Journal of Mechanics of Materials and Structures, Volume 7, pp. 1271-1285

Daniel, I.M., Abot, J.L., 2000. Fabrication, Testing and Analysis of Composite Sandwich Beams. Composite Science and Technology, Volume 60, pp. 2455-2463

Davies, J.M., 2001. Lightweight Sandwich Construction. Blackwell Science, London

Ergul, Y., Cengiz, D.A., Aleattin, K., Hasan, G., 2003. Strength and Properties of Lightweight Concrete with Basaltic Pumice and Fly Ash. Material Letter, Volume 57, pp. 2267-2270

Fajrin, J., Zhuge, Y., Bullen, F., Wang, H., 2011. The Implementation of Statistical Inference to Study the Bending Strength of Sustainable Hybrid Sandwich Panel. Advanced Material Research, Volume 250-253, pp. 956-961 
Fajrin, J., Zhuge, Y., Bullen, F., Wang, H., 2011. Flexural Strength of Sandwich Panel with Lignocellulosic Composites Intermediate Layer - A Statistic Approach. International Journal of Protective Structures, Volume 2(4), pp. 453-464

Fajrin, J., Zhuge, Y., Bullen, F., Wang, H., 2013. Significance Analysis of Flexural Behaviour of Hybrid Sandwich Panels. Open Journal of Civil Engineering, Volume 3, pp. 1-7

Fajrin, J., Zhuge, Y., Bullen, F., Wang, H., 2016. Flexural Behavior of Hybrid Sandwich Panel with Natural Fiber Composite as the Intermediate Layer. Journal of Mechanical Engineering and Sciences, Volume 10(2), pp. 1968-1983

Firmawan, F., Othman, F., Yahya, K., Haron, Z., 2016. The Green Construction Site Index (GCSI): A Quantitative Tool used to Meet the Green Construction Concept. International Journal of Technology, Volume 7(4), pp. 530-543

Harte, A.M., Fleck, N.A., Ashby, M.F., 2000. Sandwich Panel Design using Aluminum Alloy Foam. Advanced Engineering Materials, Volume 2, pp. 219-222

Hota, G., Liang, R., 2011. Advanced Fiber Reinforced Polymer Composites for Sustainable Civil Infrastructure. In: Proceeding of International Symposium on Innovation of Structures in Civil Engineering, Xiamen, China

Kawasaki, T., Zhang, M., Kawai, S., 1999. Sandwich Panel of Veneer-overlaid Low-density Fiberboard. J Wood Sci, Volume 45, pp. 291-298

Kermany, A., 2006. Performance of Structural Insulated Panels. In: Proceedings of the Institution of Civil Engineers. Structures and Buildings, Volume 159, pp. 13-19

Kim, J.H., You, Y.C., 2015. Composite Behavior of a Novel Insulated Concrete Sandwich Wall Panel Reinforced with GFRP Shear Grids: Effects of Insulation Types. Materials, Volume 8, pp. 899-913

Lewis, J., 2003. Housing Construction in Earthquake-prone Places: Perspectives, Priorities and Projections for Development. The Australian Journal of Emergency Management, Volume 18(2), pp. 35-44

Mahfuz, H., Islam, M.S., Rangari, V.K., 2004. Response of Sandwich Composites with Nanophased Cores under Flexural Loading. Composites Part B, Volume 35(6-8), pp. $543-550$

Mamalis, A.G., Spentzas, K.N., Pantelelis, N.G., Manolakos, D.E., Ionnidis, M.B., 2008. A New Hybrid Concept for Sandwich Structures. Composite Structures, Volume 83(4), pp. 335-340

Mirzapour, A, Beheshty, M.H., Vafayan, M., 2005. The Response of Sandwich Panels with Rigid Polyurethane Foam Cores under Flexural Loading. Iranian Polymer Journal, Volume 14(12), pp. 1082-1088

Mistler, M., Valls, J.P., 2004. Vulnerability of RC Frame Structures using Lightweight Sandwich Floor Systems. In: Proceeding of $13^{\text {th }}$ World Conference on Earthquake Engineering, Vancouver, Canada

Morley, M., 2000. Building with Structural Insulated Panels. Taunton Press, Newtown, USA

Mullens, M.A., Arif, M., 2006. Structural Insulated Panels: Impact on the Residential Construction Process. Journal of Construction Engineering and Management, Volume 132(7), pp. 786-794

Sharaf. T., Shawkat, W., Fam, A., 2010. Structural Performance of Sandwich Wall Panels with Different Foam Core Densities in-one-way Bending. Journal of Composite Materials, Volume 44, pp. 2249-2236

Somayaji, S., 1995. Civil engineering materials. Prentice Hall, Englewood, New Jersey, USA.

Tracy, J.M., 2000. SIPs Overcoming the Elements. Forest Product Journal, Volume 50(3), pp. $18-27$ 
Tuwair, H., Volz, J., ElGawady, M.A., Mohamed, M., Chandrashekhara, K., Birman, V., 2016. Testing and Evaluation of Polyurthane-based GFRP Sandwich Bridge Deck Panels with Polyurethane Foam Core. Journal of Bridge Engineering, Volume 21, pp. 899-912

Kalyankar, R.R., Uddin, N., 2011. Structural Characterization of Natural Fiber Reinforced Polymer Structural Insulated Panels for Panelized Construction. Journal of Reinforced Plastic and Composites, Volume 30(11), pp. 988-994

Uddin, N., Du, W., 2014. New Thin Shell Made of Composite Structural Insulated Panels. Journal of Reinforced Plastic and Composites, Volume 33(21), pp. 1954-1965

Vaidya, A., Uddin, N., Vaidya, U., 2010. Structural Characterization of Composite Structural Insulated Panels for Exterior Wall Application. Journal of Composites for Construction, Volume 14(4), pp. 464-469

Zenkert, D., 1995. An Introduction to Sandwich Construction. Solihull, EMAS 